\title{
Online Monitoring of Crack Initiation during Fatigue Cycling of Nickel-Aluminum-Bronze Alloy using Infrared Thermography
}

B. B. Lahiri*, Aritra Sarkar, S. Bagavathiappan, R. Sandhya \& T. Jayakumar Metallurgy and Materials Group, Indira Gandhi Centre for Atomic Research, Kalpakkam, Tamil Nadu, India, PIN 603102

*Corresponding author email: bblahiri@igcar.gov.in

\begin{abstract}
Crack initiation and subsequent crack growth during high cycle fatigue testing of NickelAluminum-Bronze (NAB) samples with inherent casting defects has been evaluated by infrared thermography. Prior to fatigue testing, the presence of the defects was detected using X-ray radiography. The temperature of the samples increased during fatigue cycling due to dissipation of heat energy. IRT based temperature monitoring was used for a-priori estimation of crack initiation time. It was found that for defect-free samples approximately $90 \%$ of the fatigue life was consumed in crack initiation, whereas, for samples with large volumetric internal defects or smaller defects with significant surface proximity, crack initiation occurred much earlier. Additionally, the location of the fatigue crack and its subsequent propagation was visually mapped from the acquired infrared images during progressive cyclic loading, establishing the efficacy of IRT technique for a-priori identification of crack initiation and zone of failure during fatigue loading.
\end{abstract}

Key words: Infrared thermography, High cycle fatigue, Nickel-Aluminum-Bronze, crack 